\title{
Physicochemical Characteristics and Possible Sources of Individual Mineral Particles in a Dust Storm Episode in Beijing, China
}

\author{
Jie Li ${ }^{1}$, Longyi Shao ${ }^{1} * \mathbb{C}^{\mathbb{C}}$, Lingli Chang ${ }^{1}$, Jiaoping Xing ${ }^{1}$, Wenhua Wang ${ }^{1}$, Wenjun $\mathrm{Li}^{1}$ and \\ Daizhou Zhang 2 (D) \\ 1 State Key Laboratory of Coal Resources and Safe Mining, College of Geoscience and Surveying Engineering, \\ China University of Mining and Technology (Beijing), Beijing 100083, China; jieli_lj@163.com (J.L.); \\ linglilp@126.com (L.C.); xingjiaoping@126.com (J.X.); whwang91@126.com (W.W.); \\ liwenjun_620@126.com (W.L.) \\ 2 Faculty of Environmental and Symbiotic Sciences, Prefectural University of Kumamoto, \\ Kumamoto 862-8502, Japan; dzzhang@pu-kumamoto.ac.jp \\ * Correspondence: ShaoL@cumtb.edu.cn; Tel.: +86-10-6233-9303
}

Received: 8 June 2018; Accepted: 12 July 2018; Published: 16 July 2018

\begin{abstract}
Beijing frequently experiences dust storms during spring, which result in deteriorated visibility and cause negative health impacts. In this paper, the dust particles were collected during a dust storm episode on 4-5 May 2017 in Beijing, and the samples before and after the dust storm were also collected. The morphology and elemental and mineralogical compositions of the dust samples were investigated using a transmission electron microscope equipped with an energy-dispersive $X$-ray spectrometer (TEM-EDX) and X-ray diffraction (XRD). The TEM-EDX results showed that the particles in the dust samples were mainly Si-rich, Ca-rich, S-rich, Fe-rich, Al-rich, Ti-rich, K-rich, Na-rich and $\mathrm{Mg}$-rich particles. The XRD results demonstrated that the minerals in $\mathrm{PM}_{10}$ samples were mainly clay, calcite, quartz, dolomite, plagioclase, potassium feldspar and hematite, in descending order of their contents. The clay minerals, having the highest content, were mainly kaolinite, chlorite and illite. The mixing state and aging degree of mineral particles before, during and after the dust storm episode behaved very differently. The mineral particles collected before and after the dust storm tended to have an internal mixing state, dominated by the S-rich particles internally mixed with alkaline mineral particles, revealing a more serious ageing degree. The mineral particles collected during the dust storm did not show clear internal mixing, revealing a less serious ageing degree. The amount of the Si-rich, Al-rich, Ca-rich and Ti-rich particles was highest during the dust storm, indicating that these particles mainly originated from long-distance transportation. The S-rich, Fe-rich, K-rich, $\mathrm{Na}$-rich and Mg-rich particles were mainly enriched in the samples before and after the dust storm episode, indicating that they mainly originated from local sources. A comparison of the values of $\mathrm{S} /(\mathrm{Si}+\mathrm{Al})$ in the individual particles with the particle sizes revealed that the finer mineral particles were associated with higher $S$ contents before and after the dust storm, while the coarse particles were associated with lower $S$ contents during the dust storm.
\end{abstract}

Keywords: individual mineral particle; dust storm; TEM-EDX; XRD; mixing state; Beijing

\section{Introduction}

Mineral aerosols are important parts of tropospheric aerosols. The amount of mineral aerosols that enters the atmosphere globally each year is about $1000-3000 \mathrm{Tg}$, accounting for about half of the total contents of aerosols in the troposphere [1]. The dust aerosols in China mainly originate from the Taklamakan Desert, Hexi Corridor and Hetao areas [2]. The emissions intensity in Beijing 
is strongest in spring, followed by summer, autumn and winter [2]. The average annual emission of mineral aerosols is about $581 \mathrm{Tg}$ [2], which can affect the northern, central and southern regions of China by long-distance transport [3]. Mineral aerosols carried by dust storms can influence the global radiation balance [4-6], as well as the global biogeochemistry cycles of the atmosphere, land and ocean [7-10]. Mineral particles can act as surface reaction sites for various atmospheric reactions in the troposphere. Additionally, they can influence weather and climate, as well as accelerate the conversion of primary pollutants to secondary pollutants in the atmosphere [11]. In the meantime, the inhomogeneous chemical reactions on the surface of mineral particles have an important influence on global biogeochemical cycles [12,13]. The alkaline mineral particles, such as the Ca-rich particles, in dust can react with $\mathrm{SO}_{2}$ to generate $\mathrm{CaSO}_{4}$ or other substances that promote the transformation of $\mathrm{SO}_{2}$. $\mathrm{NO}_{2}$ can form $\mathrm{NO}_{3}{ }^{-}$and gaseous $\mathrm{NO}$ on the surface of dry mineral particles and can generate gaseous $\mathrm{HONO}$ and $\mathrm{NO}_{3}{ }^{-}$on the surface of wet mineral particles. $\mathrm{NO}_{3}{ }^{-}$can further form nitrate on the surface of alkaline mineral particles $[14,15]$.

In recent years, the research on mineral aerosols in dust storms has attracted the attention of scholars. Most scholars have studied the particle size, mass concentration, composition, hygroscopic properties and heterogeneous reaction processes of particulate matter during dust storms by using bulk methods [16-22]. However, the analyses of the mixing state, aging degree and sources of individual mineral particles are lacking. The mixing state and the sources of mineral particles in dust storms can provide direction for regional governance, prevention and control of dust pollution in the future. The elemental composition and aging degree of mineral particles can provide a basis for the treatment of dust pollution in Beijing.

In Beijing, a dust storm event occurred on 4-5 May 2017. We sampled the mineral particles before, during and after this dust storm episode. The elemental composition, mixing state, aging degree and possible sources of mineral aerosols during these different stages of the dust storm event were investigated using $\mathrm{X}$-ray diffraction (XRD) and a transmission electron microscope (TEM) equipped with an energy-dispersive $X$-ray spectrometer (EDX).

\section{Materials and Methods}

\subsection{Sample Collection}

The sampling site $\left(116^{\circ} 20^{\prime} 45.6^{\prime \prime} \mathrm{E}, 39^{\circ} 59^{\prime} 37.1^{\prime \prime} \mathrm{N}\right)$ was surrounded by residences, streets and shopping centers. It was located at the China University of Mining and Technology (Beijing) in northwestern urban Beijing and was around $1 \mathrm{~km}$ from North 4th Ring Road in Beijing. The samplers were mounted on top of a building on the campus about $18 \mathrm{~m}$ above the ground. There were no major industrial pollution sources in the area.

Aerosol samples were collected during the dust storm event from 3-5 May 2017. A single-stage cascade impactor with a $0.5-\mathrm{mm}$ diameter jet nozzle with a flow rate of $1.0 \mathrm{~L} / \mathrm{min}$ was used. The particles were collected on copper TEM grids coated with carbon film (carbon type-B, 300-mesh copper, Tianld Co., Beijing, China). The collection efficiency of this impactor is $50 \%$ for particles with an aerodynamic diameter of $0.25 \mu \mathrm{m}$ and with a density of $2 \mathrm{~g} / \mathrm{cm}^{3}$. Sampling duration varied from 30-60 s depending on the concentration of $\mathrm{PM}_{2.5}$ and $\mathrm{PM}_{10}$. These samples were used to analyze individual dust particles. Moreover, an impactor with a flow rate of $100 \mathrm{~L} / \mathrm{min}$ was used to collect $\mathrm{PM}_{10}$ on glass fiber filters with a diameter of $90 \mathrm{~mm}$ for XRD analysis. The Kestrel 4500 Pocket Weather Tracker (Nielsen-Kellerman Inc., Minneapolis, MN, USA) was used to measure wind speed, wind direction, relative humidity, barometric pressure and ambient temperature (Table 1). After collection, the samples were placed in a desiccator at $25 \pm 5^{\circ} \mathrm{C}$ and $20 \pm 3 \% \mathrm{RH}$ to prevent exposure to ambient air. Image analysis software (Leica Microsystems Image Solutions Ltd., Cambridge, UK) was used to obtain the equivalent spherical diameter of particles [23]. 


\subsection{Experimental}

Individual particles on copper TEM grids were tested by the TEM (Tecnai G²F30, FEI Ltd., Hillsboro, OR, USA). The TEM was operated with an acceleration voltage of $300 \mathrm{kV}$. The particles were inhomogeneously distributed on the TEM grids with coarser particles near the center and the finer particles at the periphery [24]. To guarantee that the analyzed particles were representative of the whole size range, 3-4 areas were chosen from the center and periphery of the sampling spot on each grid. We first found an area where particles remained largely on the copper grid and then selected 3-4 squares where particle density was moderate to observe the morphology and mixing state of individual particles. All individual particles larger than $0.1 \mu \mathrm{m}$ in the selected areas were analyzed. Elemental compositions were determined semi-quantitatively using an EDX that can detect elements heavier than C. In order to understand the element characteristics of aerosol particles in the sampling period, the EDX was applied to each particle in selected squares. A low current and small beam spot were used to avoid the effect of the electron beam on the particles. Copper was not considered in the analysis because of interference from the copper TEM grid.

The glass fiber filter with $\mathrm{PM}_{10}$ samples was tested using a D/MAX-250 (Rigaku, Tokyo, Japan) $\mathrm{X}$-ray diffractometer. The X-ray diffractometer scanned with $\mathrm{Cu} \mathrm{K} \alpha$ radiation of $40 \mathrm{kV} / 125 \mathrm{~mA}$, a scanning speed of $2^{\circ}(2 \theta) / \mathrm{min}$, a sampling distance of $0.01^{\circ}(2 \theta)$ and a scanning range of 2.6-50 for mineralogical analysis. Filter samples were cut into $5 \times 5 \mathrm{~cm}$ pieces and then placed on an aluminum sample holder for XRD qualitative analysis. Identification of minerals was conducted according to the cards published by the Joint Committee on Powder Diffraction Standards. Relative proportions of major minerals were expressed by peak intensity of the strongest reflection of each mineral. These proportions were then converted to weight percentages using the weighting ratios as shown in the Standard of the China National Petroleum Corporation (CNPC) SY / 6210-1996.

Table 1. Sample information.

\begin{tabular}{|c|c|c|c|c|c|c|c|c|}
\hline $\begin{array}{l}\text { Sample } \\
\text { No. }\end{array}$ & $\begin{array}{l}\text { Sampling Time } \\
\text { (BST) }\end{array}$ & $\begin{array}{c}\text { Temperature } \\
\left({ }^{\circ} \mathrm{C}\right)\end{array}$ & $\begin{array}{c}\text { Relative } \\
\text { Humidity (\%) }\end{array}$ & $\begin{array}{l}\text { Atmospheric } \\
\text { Pressure (hPa) }\end{array}$ & $\begin{array}{l}\text { Wind Speed } \\
(\mathrm{m} / \mathrm{s})\end{array}$ & $\begin{array}{l}\text { Wind } \\
\text { Direction }\end{array}$ & $\begin{array}{l}\text { Filter } \\
\text { Types }\end{array}$ & Remarks \\
\hline 1 & 2017.5.3 18:37 & 23.7 & 40.2 & 1006.8 & 4 & SW & \multirow{7}{*}{$\begin{array}{l}\text { The } \\
\text { copper } \\
\text { TEM grid }\end{array}$} & $\begin{array}{l}\text { Before the } \\
\text { Dust Storm }\end{array}$ \\
\hline 2 & 2017.5.4 9:01 & 24.7 & 17.5 & 1009.5 & 8 & NW & & \multirow{5}{*}{$\begin{array}{l}\text { During the } \\
\text { Dust Storm }\end{array}$} \\
\hline 3 & 2017.5 .4 12:00 & 27.5 & 13.4 & 1007.8 & 6 & $\mathrm{~W}$ & & \\
\hline 4 & 2017.5.4 18:04 & 24.3 & 17.4 & 1004.7 & 2 & NW & & \\
\hline 6 & 2017.5.5 3:00 & 19.2 & 45.2 & 1002.0 & 5 & $\mathrm{~W}$ & & \\
\hline 7 & 2017.5.5 9:47 & 19.0 & 24.9 & 1009.1 & 11 & NW & & \\
\hline 8 & 2017.5.5 12:00 & 21.3 & 17.6 & 1009.8 & 10 & NW & & $\begin{array}{l}\text { After the } \\
\text { Dust Storm }\end{array}$ \\
\hline
\end{tabular}

BST, Beijing Standard Time (UTC plus 8 h).

\section{Results}

\subsection{Concentration of Pollutants during the Sampling Period}

The concentrations of $\mathrm{PM}_{2.5}, \mathrm{PM}_{10}, \mathrm{SO}_{2}, \mathrm{NO}_{2}$ and $\mathrm{O}_{3}$ were obtained from the data center of the Ministry of Ecology and Environment of the People's Republic of China (http:/ / www.zhb.gov.cn/) during the sampling period (Figure 1). The concentrations of $\mathrm{PM}_{2.5}$ and $\mathrm{PM}_{10}$ were $29-43 \mu \mathrm{g} / \mathrm{m}^{3}$ and $46-90 \mu \mathrm{g} / \mathrm{m}^{3}$, respectively, before 6:00 on 4 May. However, the mass concentrations of $\mathrm{PM}_{2.5}$ and $\mathrm{PM}_{10}$ increased to $401 \mu \mathrm{g} / \mathrm{m}^{3}$ and $987 \mu \mathrm{g} / \mathrm{m}^{3}$, respectively, after 6:00 on 4 May. The concentrations decreased to relatively low levels until 9:00 on 5 May $\left(68-71 \mu \mathrm{g} / \mathrm{m}^{3}\right.$ and $77-96 \mu \mathrm{g} / \mathrm{m}^{3}$, respectively). During this period, the mass concentrations of $\mathrm{PM}_{2.5}$ and $\mathrm{PM}_{10}$ reached up to $574 \mu \mathrm{g} / \mathrm{m}^{3}$ and $1000 \mu \mathrm{g} / \mathrm{m}^{3}$, with the lowest mass concentrations of $253 \mu \mathrm{g} / \mathrm{m}^{3}$ and $663 \mu \mathrm{g} / \mathrm{m}^{3}$, respectively. The city experienced a serious 
dust storm episode that lasted about $27 \mathrm{~h}$ from 6:00 on 4 May to 9:00 on 5 May. According to the changes in mass concentration of particulate matter during the sampling period, the dust storm episode was divided into three stages, namely before the dust storm (18:00 on 3 May to 3:00 on 4 May), during the dust storm (3:00 on 4 May to 9:00 on 5 May) and after the dust storm (9:00 to 15:00 on 5 May). The concentrations of $\mathrm{SO}_{2}$ and $\mathrm{NO}_{2}$ were $2-10 \mu \mathrm{g} / \mathrm{m}^{3}$ and $7-41 \mu \mathrm{g} / \mathrm{m}^{3}$, respectively, which showed that levels were low in the daytime and high during the night. The highest peak was around 0:00 on 5 May, and the lowest value appeared around 12:00 on 5 May. The concentration of $\mathrm{O}_{3}$ was $35-109 \mu \mathrm{g} / \mathrm{m}^{3}$, which showed that it was high in the daytime and low during the night. The highest peak appeared at around 12:00 on 4 May, and the lowest value appeared at around 3:00 on 5 May. Overall, the variable characteristics of the concentrations of $\mathrm{SO}_{2}, \mathrm{NO}_{2}$ and $\mathrm{O}_{3}$ showed opposite trends. When the concentrations of $\mathrm{SO}_{2}$ and $\mathrm{NO}_{2}$ were relatively high, the concentration of $\mathrm{O}_{3}$ was low, whereas when the concentrations of $\mathrm{NO}_{2}$ and $\mathrm{SO}_{2}$ were low, the concentration of $\mathrm{O}_{3}$ was relatively high. This trend may have been associated with the formation of sulfates and nitrates due to the chemical reaction of $\mathrm{SO}_{2}, \mathrm{NO}_{2}$ and $\mathrm{O}_{3}$ in the atmosphere [25].

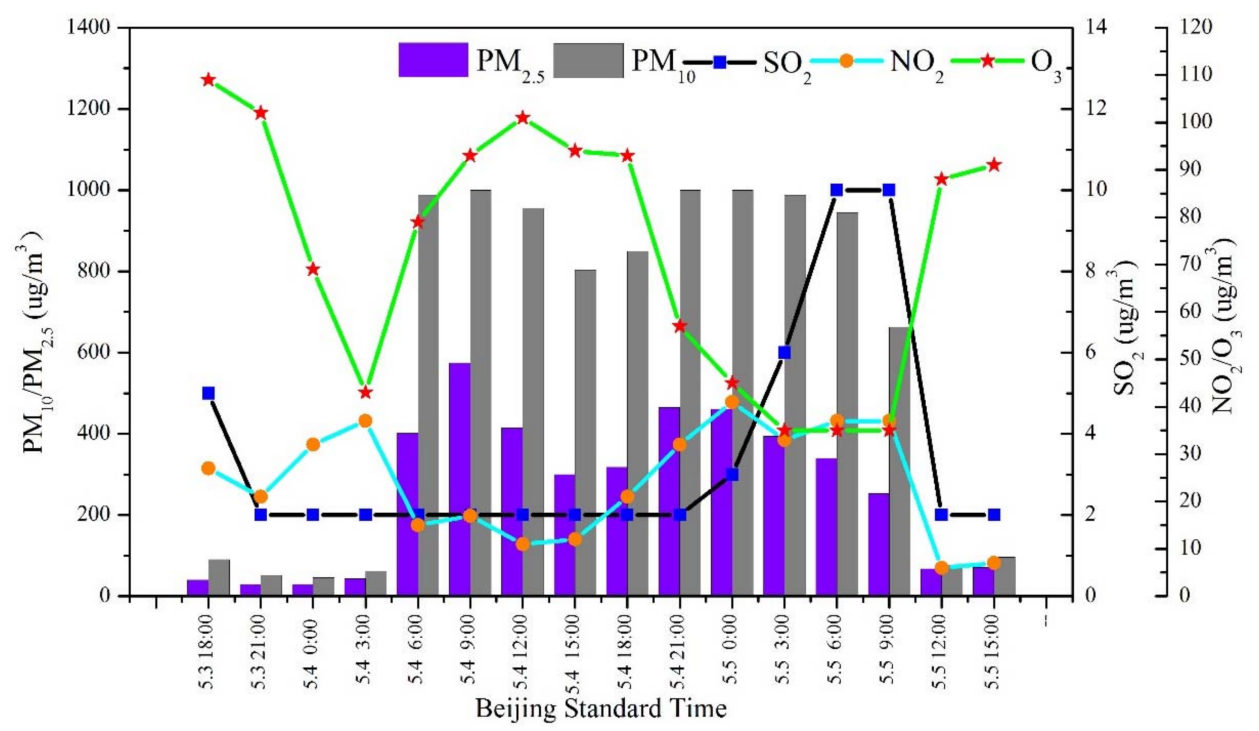

Figure 1. Changes in pollutant concentrations during the sampling period.

\subsection{Types of Mineral Particles}

According to the results from the TEM-EDX analyses, we chose 10 elements $(\mathrm{Na}, \mathrm{Mg}, \mathrm{Al}, \mathrm{Si}, \mathrm{S}, \mathrm{Cl}$, $\mathrm{K}, \mathrm{Ca}, \mathrm{Ti}$ and $\mathrm{Fe}$ ) in individual mineral particles and labeled them as "X-rich" particles according to the maximum $\mathrm{P}(\mathrm{X})$ of elements. The value of $\mathrm{P}(\mathrm{X})$ was calculated as follows:

$$
\mathrm{P}(\mathrm{X})=\mathrm{X} /(\mathrm{Na}+\mathrm{Mg}+\mathrm{Al}+\mathrm{Si}+\mathrm{S}+\mathrm{Cl}+\mathrm{K}+\mathrm{Ca}+\mathrm{Ti}+\mathrm{Fe}) \times 100 \%
$$

$P(X)$ is the weight ratio of element $X$ in an individual mineral particle [26]. According to $P(X)$, mineral particles from the dust storm were classified into nine different types, namely Si-rich, Ca-rich, S-rich, Fe-rich, Al-rich, Ti-rich, K-rich, Na-rich and Mg-rich. Under the TEM, the Si-rich, Ca-rich, Fe-rich, Al-rich, Ti-rich, K-rich and Na-rich particles always showed irregular shapes (Figure 2a,b,d-h), but the Na-rich particles were filled with much small, circular matter (Figure $2 \mathrm{~h}$ ). The S-rich particles were almost circular in shape, and most of them became volatile under the electron beam (Figure 2c). The Mg-rich particles also displayed a circular shape, and they tended to have a clear core-shell structure (Figure 2i).

The mineral particles accounted for $92.53 \%$ of the total particles during the dust storm, while they accounted for $46 \%$ and $59.76 \%$ of total particles before and after the dust storm, respectively. The mineral particles during the dust storm were further classified according to the values of $\mathrm{Si} / \mathrm{Al}$ 
(content ratio) and the peaks of other elements in the EDX results [27]. When the value of $\mathrm{Si} / \mathrm{Al}$ was approximately equal to one, it was kaolinite. If the value of $\mathrm{Si} / \mathrm{Al}$ was equal to 1-2 and had higher $\mathrm{K}$ contents, it was illite. In addition, if the value of $\mathrm{Si} / \mathrm{Al}$ was approximately equal to 2 , the individual particles usually contained higher contents of Fe and $\mathrm{Mn}$ and were recognized as chlorite. When the $\mathrm{Si} / \mathrm{Al}$ value was approximately equal to 3, the particle was feldspar (e.g., plagioclase or potassium feldspar). Plagioclase contained high contents of $\mathrm{Na}$ or $\mathrm{Ca}$, and potassium feldspar contained higher contents of K. According to the energy spectra, calcite showed a higher peak of Ca elements, followed by $\mathrm{O}$ elements. Dolomite showed higher peaks of $\mathrm{Mg}$ and $\mathrm{Ca}$ elements. Quartz had higher peaks of Si and $\mathrm{O}$ elements. Moreover, hematite had higher peaks of $\mathrm{Fe}$ and $\mathrm{O}$ elements (Figure 3). Among these minerals, kaolinite $\left(\mathrm{Al}_{4}\left[\mathrm{Si}_{4} \mathrm{O}_{10}\right](\mathrm{OH})_{8}\right)$, chlorite $\left((\mathrm{Mg}, \mathrm{Fe})_{4.75} \mathrm{Al}_{1.25}\left[\mathrm{Al}_{1.25} \mathrm{Si}_{2.75} \mathrm{O}_{10}\right](\mathrm{OH})_{8}\right)$ and illite $\left(\mathrm{K}_{2-x} \mathrm{Al}_{4}\left[\mathrm{Al}_{2-\mathrm{x}} \mathrm{Si}_{6+\mathrm{x}} \mathrm{O}_{20}\right](\mathrm{OH})_{4}\right)$ belong to the layered silicate minerals and are also called clay minerals. Plagioclase $\left(\mathrm{Na}\left[\mathrm{AlSi}_{3} \mathrm{O}_{8}\right]-\mathrm{Ca}\left[\mathrm{Al}_{2} \mathrm{Si}_{2} \mathrm{O}_{8}\right]\right)$ and potassium feldspar $\left(\mathrm{K}\left[\mathrm{AlSi}_{3} \mathrm{O}_{8}\right]\right)$ belong to the framework of silicate minerals and can be referred to as the minerals of feldspar groups. Calcite $\left(\mathrm{CaCO}_{3}\right)$ and dolomite $\left(\mathrm{MgCa}\left[\mathrm{CO}_{3}\right]_{2}\right)$ are part of the carbonate minerals. Quartz $\left(\mathrm{SiO}_{2}\right)$ and hematite $\left(\mathrm{Fe}_{2} \mathrm{O}_{3}\right)$ are oxide minerals.
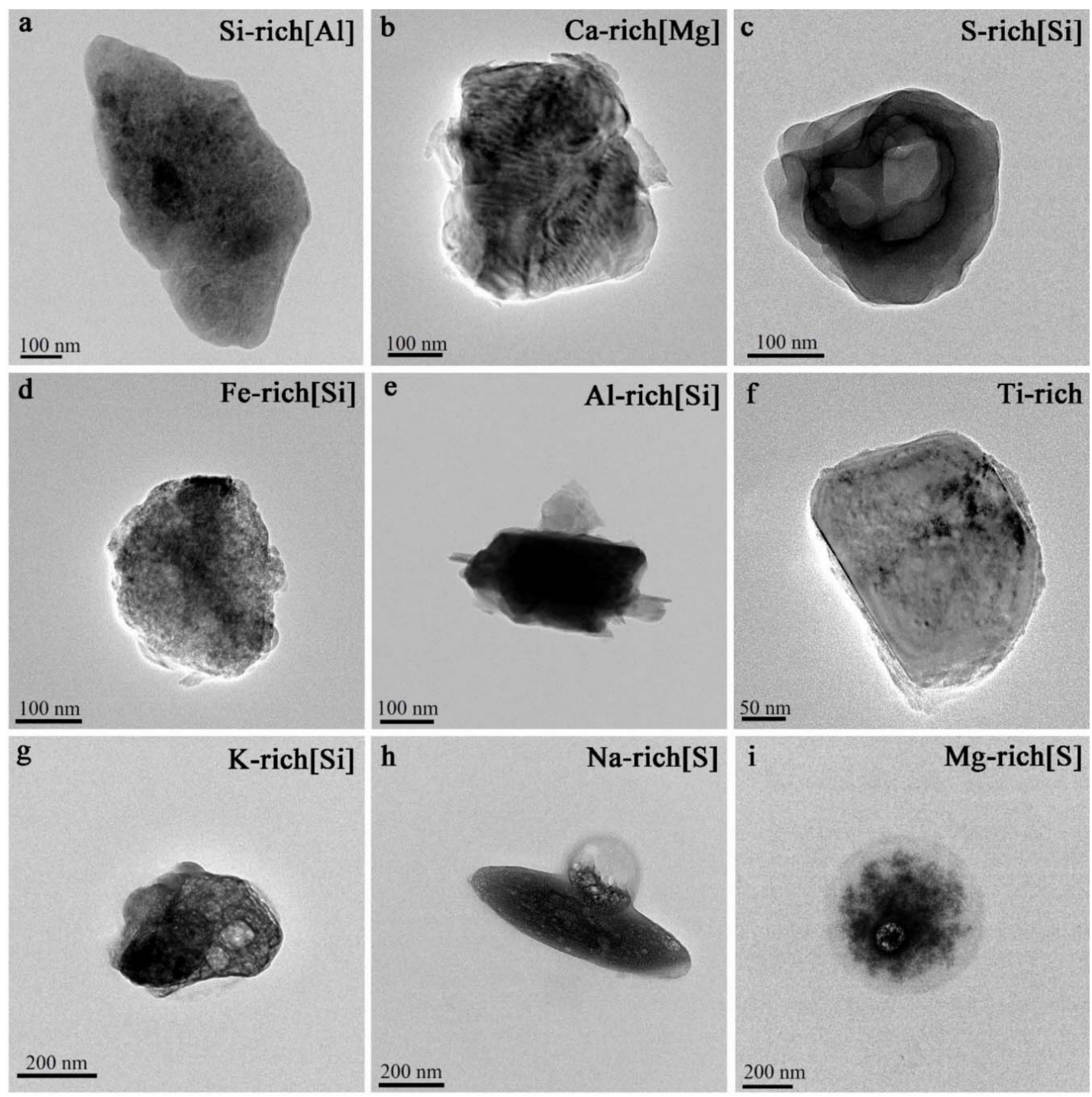

Figure 2. The morphology and types of mineral particles collected during different stages of the dust storm. The elements in square brackets represent the second highest contents. 


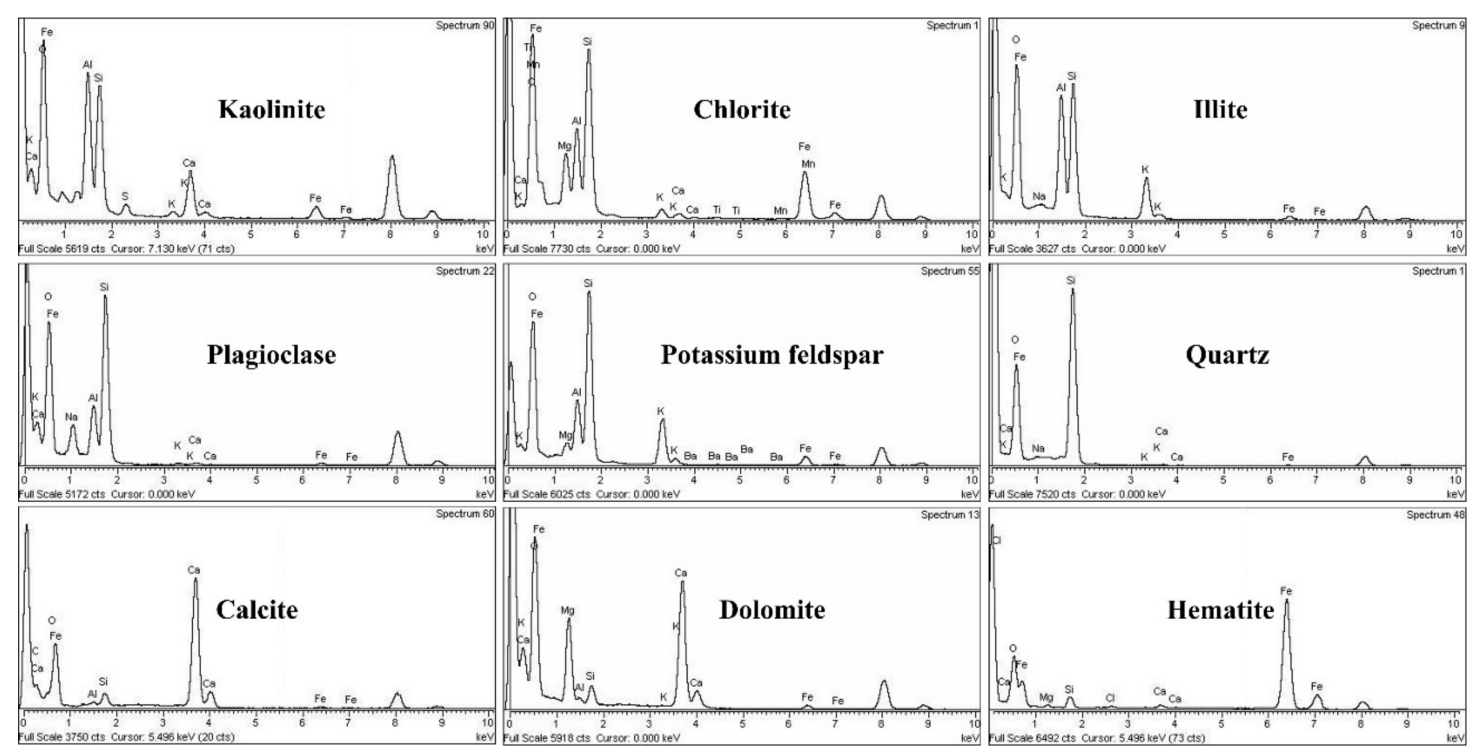

Figure 3. Different minerals detected by EDX during the dust storm.

\subsection{XRD Analysis}

In order to verify the reliability of the method of mineral classification based on the results of the EDX (the values of $\mathrm{Si} / \mathrm{Al}$ and the peak values of elements) and to determine the contents of the various types of minerals, we used $\mathrm{XRD}$ to analyze the $\mathrm{PM}_{10}$ samples acquired during the dust storm. The XRD result showed that the samples contained kaolinite, chlorite, illite, plagioclase, potassium feldspar, quartz, calcite, dolomite and hematite (Figure 4), which was consistent with the results of the classification based on the EDX. The results of the total rock quantitative analysis showed that the contents of clay minerals (kaolinite, chlorite and illite) and calcite were the highest and reached $51.4 \%$ and $17.6 \%$, respectively, followed by quartz $(13.3 \%)$, dolomite $(8.4 \%)$, plagioclase $(4.8 \%)$ and potassium feldspar (3.6\%). The content of hematite was lowest and accounted for $0.9 \%$ (Figure 5).

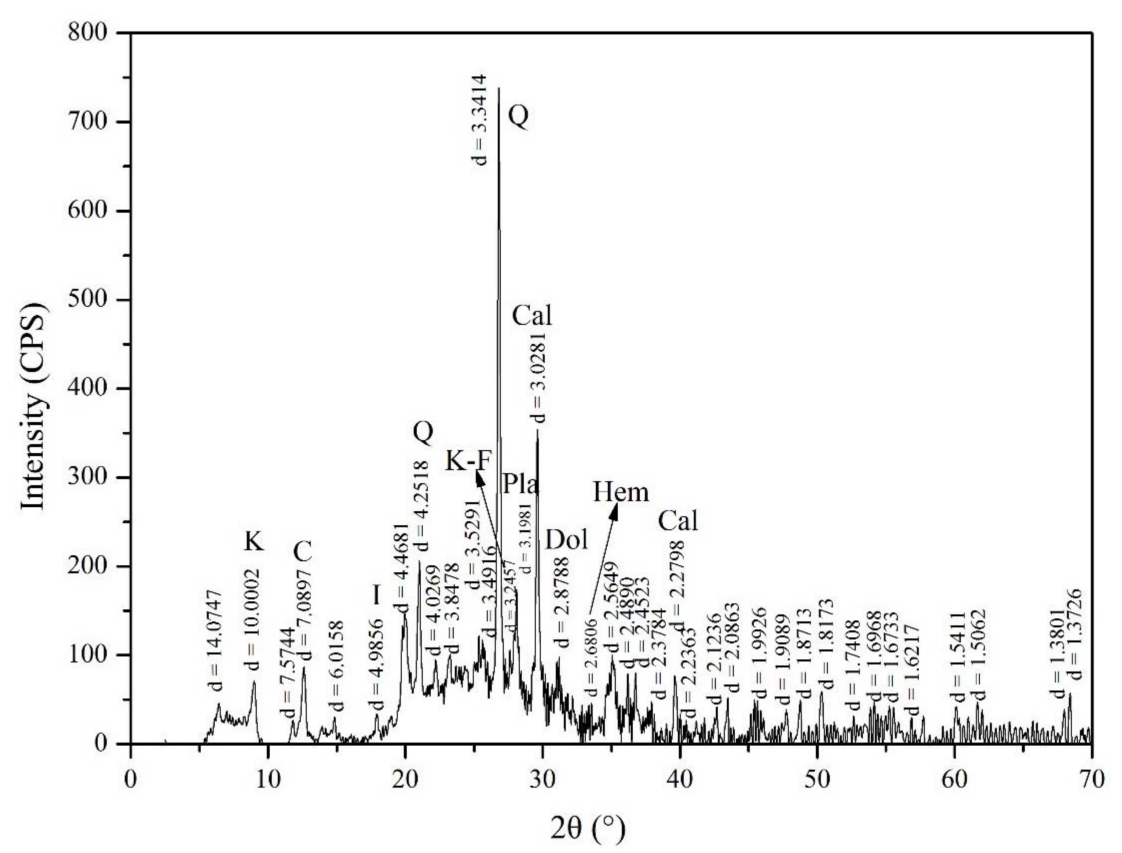

Figure 4. $\mathrm{XRD}$ pattern of $\mathrm{PM}_{10}$ collected during the dust storm. I, illite; K, kaolinite; Q, quartz; C, chlorite; Cal, calcite; Dol, dolomite; K-F, potassium feldspar; Pla, plagioclase; Hem, hematite. 


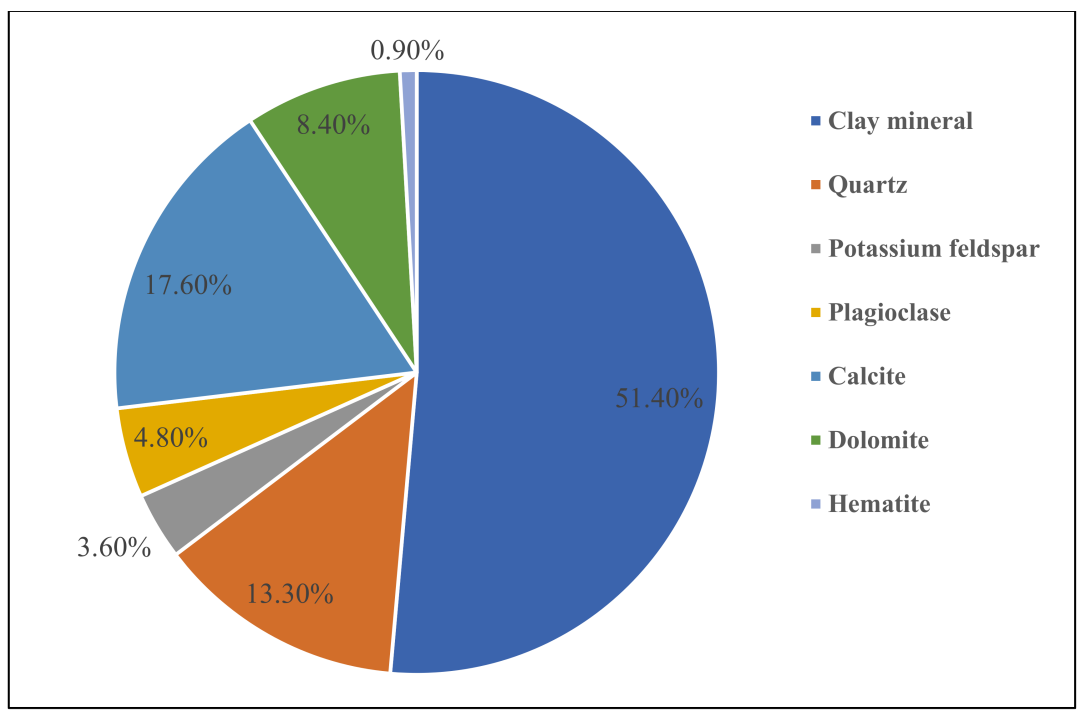

Figure 5. Proportion of different mineral types as determined by $\mathrm{XRD}$ for $\mathrm{PM}_{10}$ collected during the dust storm.

\section{Discussion}

\subsection{Sources of Mineral Aerosol during the Sampling Period}

Isentropic backward trajectories of mineral aerosols in the three stages were calculated using the HYSPLIT (hybrid single-particle Lagrangian integrated trajectory) model [28,29]. Three 24-h backward trajectories were started at an altitude of $500 \mathrm{~m}$ above the sampling site (Figure 6). We found that the sources of mineral aerosols in the three stages were very different. The mineral aerosols before the dust storm (18:00 on 3 May 2017) mainly originated from the southern area of Beijing, Hebei, Shandong and Jiangsu provinces, which were the most serious air pollution areas in the North China Plane. The mineral aerosols during the dust storm (9:00 on 4 May 2017) mainly originated from the Gobi Desert in the midwest of Inner Mongolia and west of Mongolia; these areas are important source areas for Asian dust storms. The results showed that the atmosphere in Beijing was dominated by dust during this stage. The mineral aerosols after the dust storm (12:00 on 5 May 2017) originated from the center of Inner Mongolia and the mideast of Mongolia. The concentrations of $\mathrm{PM}_{2.5}$ and $\mathrm{PM}_{10}$ decreased to relatively low levels during this stage (Figure 1).

\subsection{Mixing State and Aging Characteristics of Mineral Particles}

The mixing state of individual particles can be classified as internal mixing and external mixing. Internal mixing mineral particles are mainly formed by heterogeneous reactions with other pollutants. The chemical reaction process of mineral particles in the atmosphere is considered the aging process of mineral particles. The more serious the atmospheric chemistry reaction, the higher the aging degree of mineral particles. We found internal mixing particles in the samples before and after the dust storm. The relative number of internal mixing particles before the dust storm was the highest and accounted for $52.27 \%$ of the total particles, followed by internal mixing particles in the samples after the dust storm (16.33\%). The mixing particles before the dust storm were the S-rich particles that were internally mixed with alkaline mineral particles, such as the K-rich, Ca-rich or Na-rich particles (Figure $7 \mathrm{a}-\mathrm{c}$ ). This indicated that acid gas produced heterogeneous chemical reactions on the surface of the alkaline mineral particles, which resulted in the formation of secondary particles because of the higher concentrations of $\mathrm{SO}_{2}$ and $\mathrm{NO}_{2}$ (Figure 1) and higher relative humidity of the atmosphere during this sampling period (Table 1) [30]. The S-rich particles that were internally mixed with other mineral particles were not found during the dust storm (Figure $7 \mathrm{~d}-\mathrm{f}$ ). This result indicated that 
relatively strong heterogeneous reactions did not occur on the surface of mineral particles due to lower concentrations of $\mathrm{SO}_{2}$ and $\mathrm{NO}_{2}$ (Figure 1) and lower relative humidity during this sampling period (Table 1). After the dust storm, the S-rich particles that were internally mixed with the Na-rich particles were found (Figure $7 \mathrm{~g}, \mathrm{i}$ ). However, the relative number percentage of internal mixing particles was lower than that before the dust storm. Some mineral particles did not mix with the S-rich particles (Figure $7 \mathrm{~h}$ ). This result showed that heterogeneous reactions with $\mathrm{SO}_{2}$ and other gaseous pollutants occurred on the surface of the mineral particles after the dust storm, but the reactions were not serious compared with those before the dust storm. In addition, some mineral particles transported over long distances remained in the atmosphere and did not react with gaseous pollutants. A large number of internal mixing mineral particles were found before and after the dust storm by comparing the mixing state and the proportion of the mixed particles in the three stages. These mixing particles with severe aging degree were created by heterogeneous reactions between local pollutants and mineral particles. However, the mineral particles during the dust storm did not mix with the S-rich particles, which were relatively fresh mineral particles. This also indicated that the atmospheric environment experienced a whole process of transformation from a hazy day to a dust day and was gradually restored to a hazy day during the sampling period in Beijing.

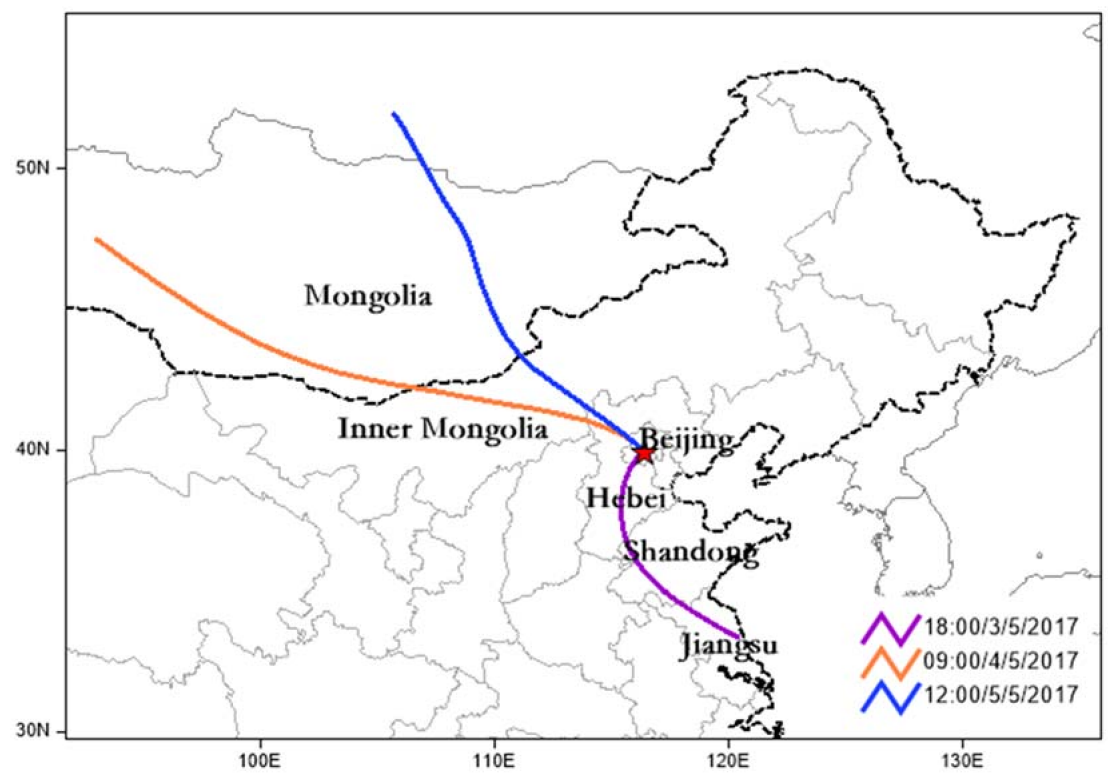

Figure 6. Isentropic backward trajectories of mineral aerosols before, during, and after the dust storm. The purple line represents the backward trajectory of the mineral aerosols before the dust storm (18:00 on 3 May 2017). The orange line represents the backward trajectory of the mineral aerosols during the dust storm (9:00 on 4 May 2017). The blue line represents the backward trajectory of the mineral aerosols after the dust storm (12:00 on 5 May 2017).

\subsection{Elemental Changes in Mineral Particles}

In order to compare mineral particles in the three stages, the relative number percentages of mineral particles containing different elements and types in different stages of the dust storm were studied. The results are shown in Figure 8. In terms of elements of mineral particles (Figure 8a), the relative number percentages of mineral particles containing $C$ and $S$ during the dust storm were much lower than those before and after the dust storm. Among them, the relative number percentage of mineral particles with mass fractions of $S$ greater than $5 \%$ accounted for only $6.12 \%$. On the contrary, the relative number percentages of particles containing $\mathrm{Mg}, \mathrm{Al}, \mathrm{Fe}$ and $\mathrm{Ca}$ during the dust storm were much higher than those before and after the dust storm. Particles containing other elements (e.g., $\mathrm{O}, \mathrm{Na}, \mathrm{Si}, \mathrm{Cl}$ and $\mathrm{K}$ ) had no significant differences. In terms of types of mineral particles 
(Figure $8 b$ ), the relative number percentages of the S-rich and K-rich particles before and after the dust storm were much higher than those during the dust storm. The relative number percentage of the Si-rich particles during the dust storm was the highest compared with other mineral particles and was significantly higher than that before and after the dust storm. In addition, the Na-rich and Mg-rich particles were not found during the dust storm. The relative number percentage of the Fe-rich particles after the dust storm was higher than that before and during the dust storm. The Al-rich and Ti-rich particles only appeared in the mineral aerosols collected during the dust storm. Therefore, the mineral particles collected before and after the dust storm contained anthropogenic pollutants, such as sulfurand carbon-containing compounds, which was consistent with the finding that the mineral particles collected in the three stages had different sources.
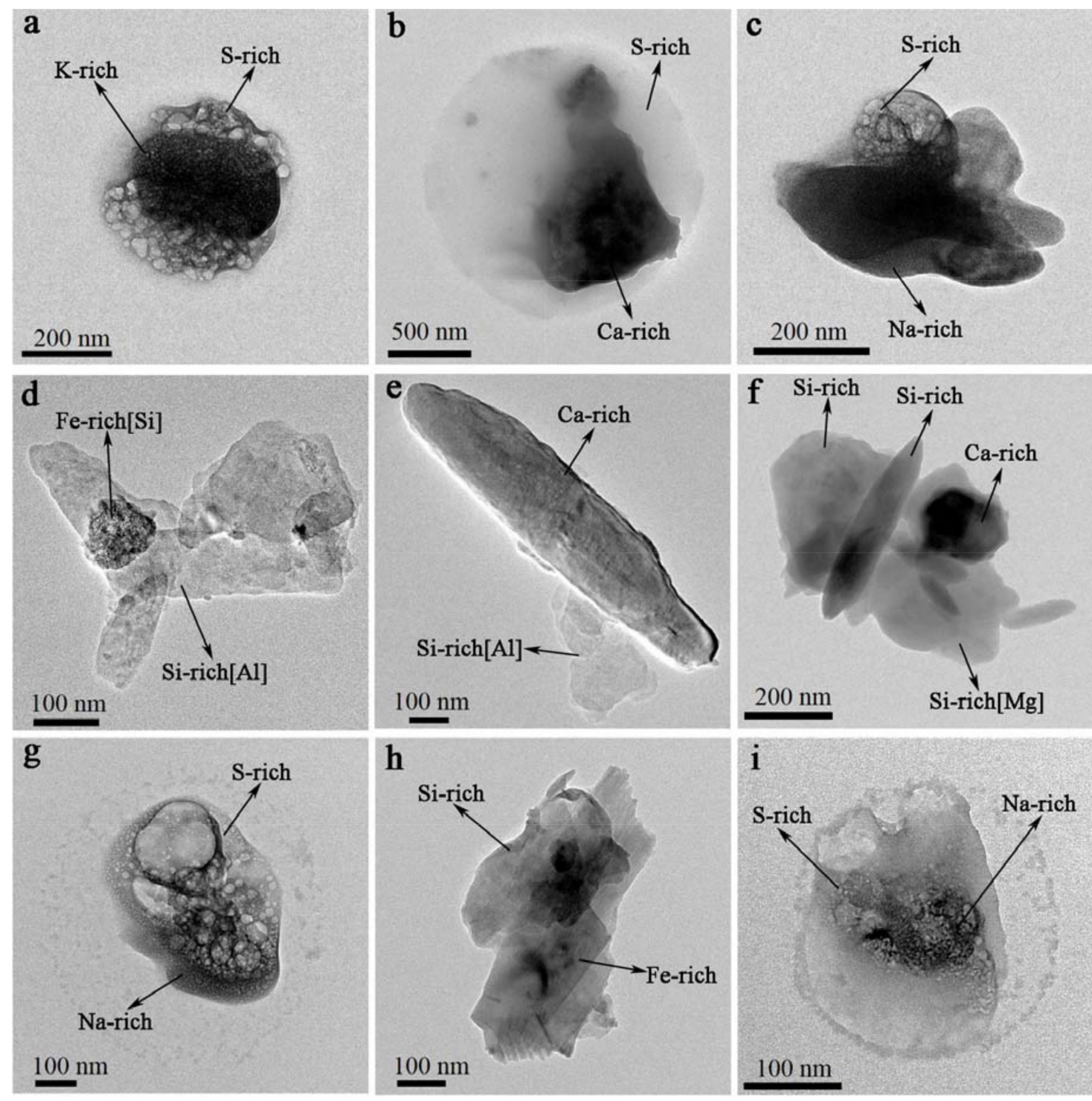

Figure 7. Mixing state of mineral particles. (a) shows the S-rich particles internally mixed with the K-rich particles. (b) shows the S-rich particles internally mixed with the Ca-rich particles. (c) shows the S-rich particles internally mixed with the Na-rich particles. (d-f,h) show the fresh mineral particles. (g) shows the Na-rich particles internally mixed with S-rich particles. (g,i) show the S-rich particles internally mixed with the Na-rich particles. $(\mathbf{a}-\mathbf{c})$ show the internal mixing particles collected before the dust storm. (d-f) show the fresh mineral particles collected during the dust storm. $(\mathbf{g}-\mathbf{i})$ show the internal mixing particles and the fresh mineral particles collected after the dust storm. 

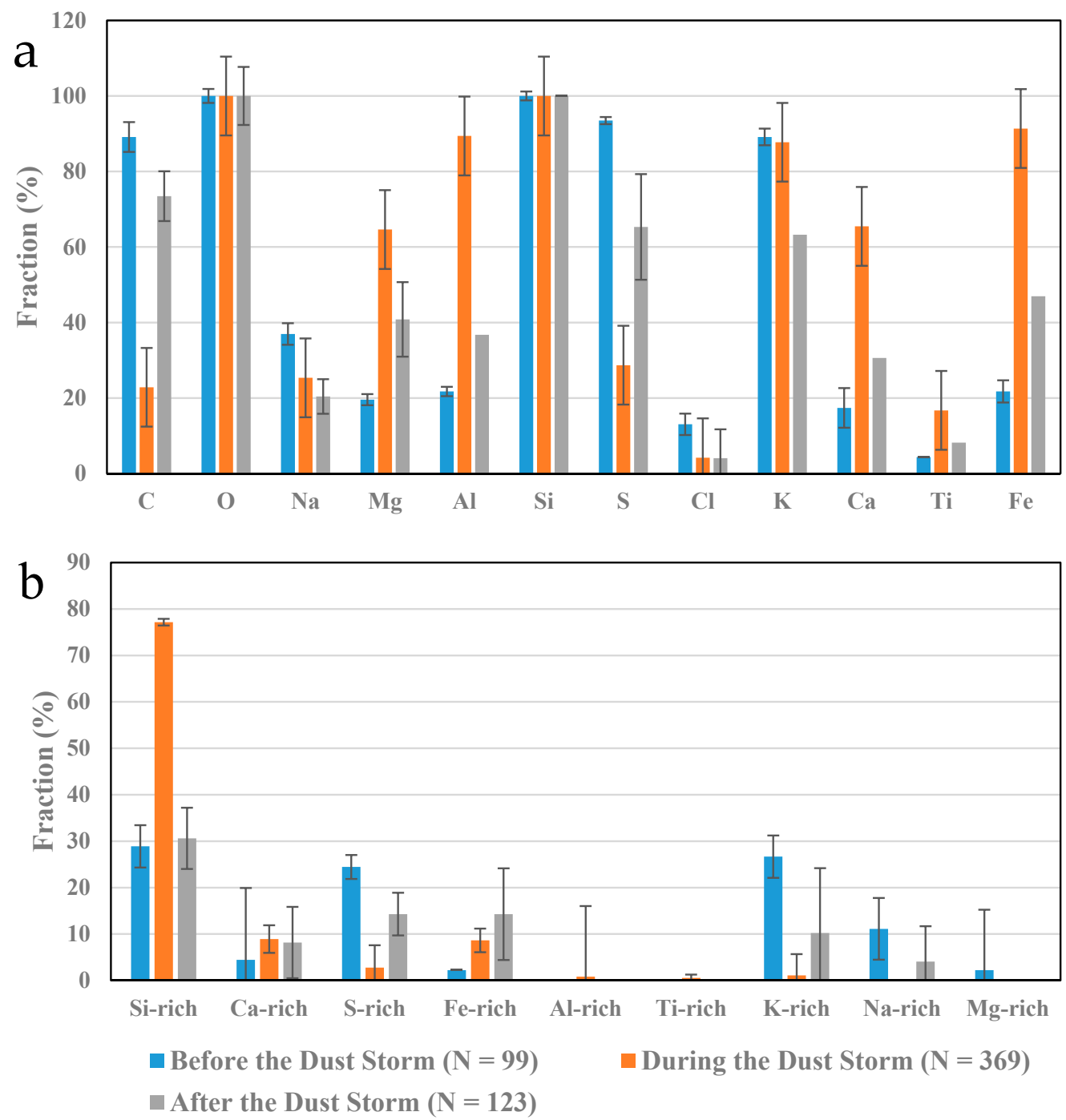

Figure 8. The relative number percentages of particles containing different elements and types in different stages of the dust storm. $\mathrm{N}$ represents the number of analyzed particles.

Although the relative number percentage of Si-containing particles was consistent before, during and after the dust storm, the relative number percentage of the Si-rich particles during the dust storm was clearly higher than that before and after the dust storm. This result showed that the Si-rich particles mainly originated from long-distance transport of dust according to the backward trajectories of mineral aerosols during the dust storm (Figure 6). Moreover, the relative number of Al-containing particles occupied a large proportion during the dust storm, thereby indicating that the Si-rich particles were mainly feldspar and clay minerals, whose components were mainly aluminosilicate. The relative number percentage of Ca-containing particles during the dust storm was much higher than that before and after the dust storm, but the relative number percentage of the Ca-rich particles during and after the dust storm was clearly higher than that before the dust storm. This result showed that the Ca-rich particles mainly originated from the long-distance transport of dust and then remained in the local air mass. These Ca-rich particles were mainly calcite and dolomite according to the XRD results of bulk samples (Figure 5). S-containing and K-containing particles were in accordance with the changes in the relative number percentages of the S-rich and K-rich particles in the three stages. According to the EDX results, the S-rich particles composed of sulfates, including $\mathrm{NaSO}_{4}, \mathrm{CaSO}_{4}$ and $\mathrm{MgSO}_{4}$, were generated by the chemical reaction of $\mathrm{SO}_{2}$ and mineral particles in the atmosphere. These particles are an important constituent of atmospheric particulate matter during hazy days in the 
North China Plain [11,31]. The K-rich particles composed mainly of $\mathrm{K}_{2} \mathrm{SO}_{4}$ and $\mathrm{KNO}_{3}$ were important tracers for biomass and biofuel combustion [24,32-34]. The K-rich particles mainly originated from anthropogenic emissions of biomass burning in suburban Beijing according to the isentropic backward trajectories of mineral aerosols before the dust storm. Although the relative number percentage of Fe-containing particles was the highest, there were few Fe-rich particles during the dust storm. On the contrary, the relative number percentage of the Fe-rich particles after the dust storm was much higher. This result indicated that the relative number percentage of Fe-containing particles was much higher, but the content of Fe was relatively lower. The Fe-rich particles sampled after the dust storm mainly originated from road and construction dust [35-37]. The Al-rich and Ti-rich particles mainly originated from the long-distance transport of dust and were trace minerals because they did not appear before or after the dust storm. The Na-rich particles mainly originated from Beijing and surrounding areas because they did not appear during the dust storm. The relative number percentage of $\mathrm{Mg}$-containing particles was higher during the dust storm, thereby suggesting that the mineral aerosols transported over a long distance had many Mg-containing particles. However, it should be mentioned that the content of $\mathrm{Mg}$ in these individual particles was low. The Mg-rich particles only appeared in the mineral aerosols sampled before the dust storm and mainly originated from Beijing and surrounding areas. Therefore, the Si-rich, Al-rich, Ca-rich and Ti-rich particles mainly originated from the long-distance transport of dust and were mostly clay, feldspar, quartz, dolomite and calcite, which are minerals of non-local sources. The S-rich, Fe-rich, K-rich, Na-rich and Mg-rich particles mainly originated from Beijing and surrounding areas.

\subsection{Sulfur in Mineral Particles}

Although the dust storm particles were dominated by a higher percentage of $\mathrm{Si}$ and $\mathrm{Al}$, a significant amount of $S$ was also noticed in these mineral particles. The mineral particles containing $\mathrm{S}$ were likely to be associated with atmospheric chemical reactions of the anthropogenic pollutants. In order to evaluate the chemical reactions between mineral particles and anthropogenic pollutants, we focused on the ratio of $\mathrm{S} /(\mathrm{Si}+\mathrm{Al})$ in individual particles collected in different stages of the dust storm. Figure 9 shows the values and sizes of mineral particles in different stages of the dust storm. The relative number percentages of mineral particles with values of $\mathrm{S} /(\mathrm{Si}+\mathrm{Al})$ higher than 1.0 before, during and after the dust storm were $50 \%, 3.45 \%$ and $24.44 \%$, respectively. The equivalent spherical diameters of S-containing particles before, during and after the dust storm were mostly less than $1 \mu \mathrm{m}$. The relative number percentage of S-containing particles before the dust storm was higher than that collected during and after the dust storm (Figure 8a). This result indicated that homogeneous and heterogeneous chemical reactions occurred in mineral particles before the dust storm. The relative number percentage of S-containing particles during the dust storm was the lowest (Figure 8a). The fine S-containing particles mainly originated from local sources [38]. The contents of $S$ in mineral particles larger than $1 \mu \mathrm{m}$ were extremely low during the dust storm. The coarse mineral particles were mainly clay and feldspar according to the XRD results of bulk samples. The relative number percentage of S-containing particles increased abruptly after the dust storm (Figure 8a). The contents of sulfur in fine mineral particles after the dust storm were higher than those in fine mineral particles collected during the storm. This result indicated that the degree of atmospheric chemical reaction between mineral particles and $\mathrm{SO}_{2}$ or other pollutants was more serious compared with that during the dust storm. Therefore, mineral particles with small sizes were associated with higher $\mathrm{S}$ contents before and after the dust storm. Coarse mineral particles transported over long distances were associated with lower $\mathrm{S}$ contents during the dust storm. These minerals were mainly clay and feldspar. Although some mineral particles with small sizes during the dust storm contained $S$, the relative number of S-containing particles was few. 


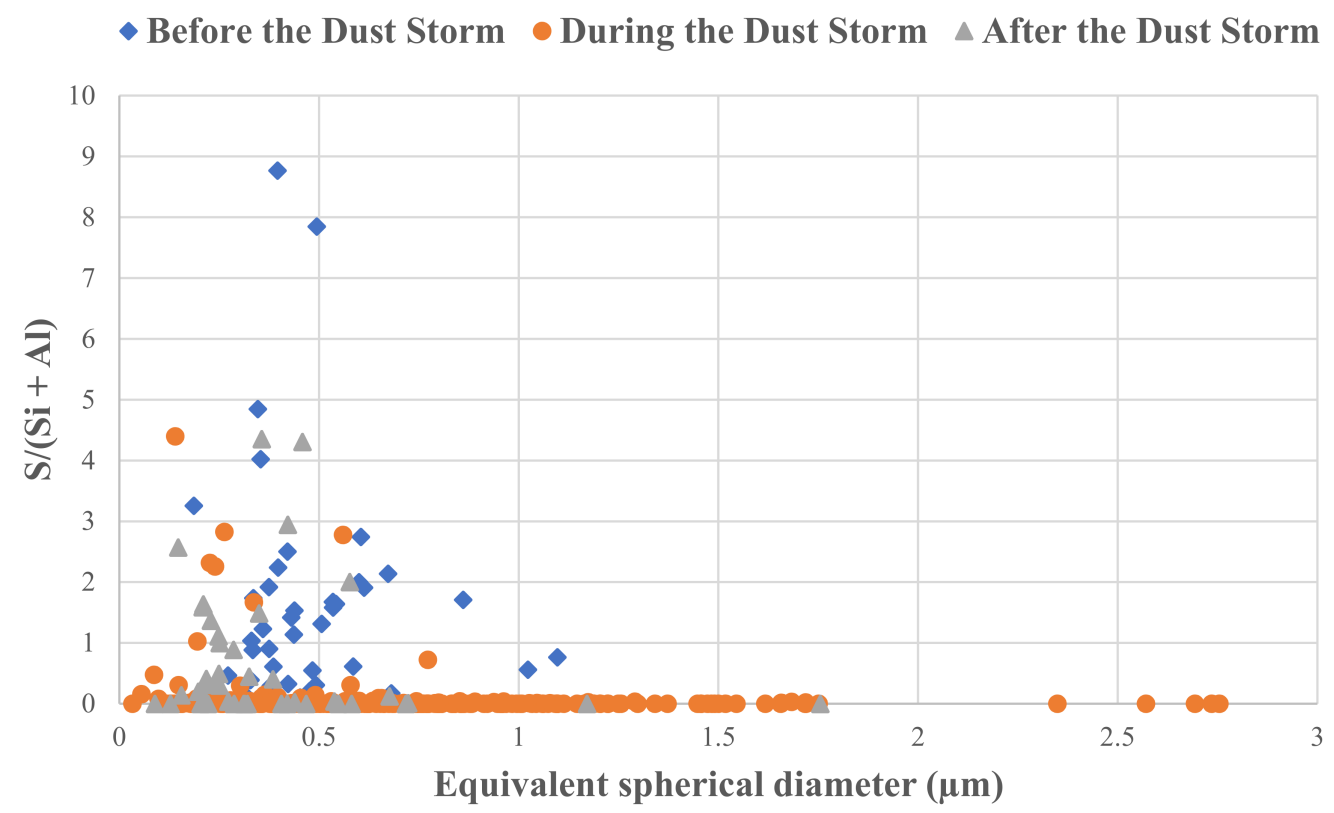

Figure 9. The value of $\mathrm{S} /(\mathrm{Si}+\mathrm{Al})$ in individual particles as a function of particle diameter.

\section{Conclusions}

The mineral particles were mainly the Si-rich, Ca-rich, S-rich, Fe-rich, Al-rich, Ti-rich, K-rich, Na-rich and Mg-rich particles in different stages of the dust storm. Clay minerals (51.14\%), plagioclase $(4.8 \%)$, potassium feldspar (3.6\%), quartz $(13.3 \%)$, calcite $(17.6 \%)$, dolomite $(8.4 \%)$ and hematite $(0.9 \%)$ were identified in samples collected during the dust storm.

The mixing mineral particles collected before and after the dust storm were the S-rich particles internally mixed with alkaline mineral particles, and their degree of aging was serious. The mineral particles collected during the dust storm did not show clear internal mixing, thereby revealing a less serious degree of ageing.

The Si-rich, Al-rich, Ca-rich and Ti-rich particles mainly originated from the long-distance transport of dust. Most of these particles were clay, feldspar, dolomite, calcite and quartz. The S-rich, Fe-rich, K-rich, Na-rich and Mg-rich particles mostly originated from local pollution sources in Beijing.

Mineral particles with small sizes before and after the dust storm were associated with higher $\mathrm{S}$ contents. Coarse mineral particles transported over long distances were associated with lower $\mathrm{S}$ contents during the dust storm.

Author Contributions: Conceptualization, J.L. and L.S.; Data Curation, J.L. and W.W.; Formal Analysis, J.L., L.S. and J.X.; Investigation, J.L., L.C. and W.L.; Methodology, J.L., L.S., L.C., J.X., W.W., W.L. and D.Z.; Project Administration, J.L. and L.S.; Resources, L.S.; Software, L.S.; Supervision, L.S. and D.Z.; Validation, L.S. and D.Z.; Visualization, J.L., L.S., J.X. and W.W.; Writing-Original Draft, J.L.; Writing-Review \& Editing, J.L., L.S. and D.Z.

Funding: This research was funded by the Projects of International Cooperation and Exchanges NSFC (Grant No. 41571130031) and the National Basic Research Program of China (Grant No. 2013CB228503).

Acknowledgments: This work was supported by the Projects of International Cooperation and Exchanges NSFC (Grant No. 41571130031) and the National Basic Research Program of China (Grant No. 2013CB228503).

Conflicts of Interest: The authors declare no conflict of interest.

\section{References}

1. D'Almeida, G.A. On the variability of desert aerosol radiative characteristics. J. Geophys. Res. Atmos. 1987, 92, 3017-3026. [CrossRef]

2. Guo, J.; Yin, Y.; Wang, Y.W.; Kang, H.Q.; Xiao, H.; Chen, K.; Hao, J. Numerical study of the dust distribution, source and sink, and transport features over East Asia. Chin. Environ. Sci. 2017, 37, 801-812. 
3. Ginoux, P.; Prospero, J.M.; Torres, O.; Chin, M. Long-term simulation of global dust distribution with the GOCART model: Correlation with North Atlantic Oscillation. Environ. Model. Softw. 2004, 19, 113-128. [CrossRef]

4. Huang, J.; Guo, J.; Wang, F.; Liu, Z.; Jeong, M.J.; Yu, H.; Zhang, Z. CALIPSO inferred most probable heights of global dust and smoke layers. J. Geophys. Res. Atmos. 2015, 120, 5085-5100. [CrossRef]

5. Feingold, G.; Mccomiskey, A.; Yamaguchi, T.; Johnson, J.S.; Carslaw, K.S.; Schmidt, K.S. New approaches to quantifying aerosol influence on the cloud radiative effect. Proc. Natl. Acad. Sci. USA 2016, 113, 5812-5819. [CrossRef] [PubMed]

6. Xu, H.; Guo, J.; Wang, Y.; Zhao, C.; Zhang, Z.; Min, M.; Miao, Y.; Liu, H.; He, J.; Zhou, S. Warming effect of dust aerosols modulated by overlapping clouds below. Atmos. Environ. 2017, 166, 393-402. [CrossRef]

7. Wang, H.; Shi, G.Y.; Li, S.Y.; Li, W.; Wang, B.; Huang, Y.B. The impacts of optical properties on radiative forcing due to dust aerosol. Adv. Atmos. Sci. 2006, 23, 431-441. [CrossRef]

8. Duce, R.A.; Unni, C.K.; Ray, B.J.; Prospero, J.M.; Merrill, J.T. Long-range atmospheric transport of soil dust from Asia to the tropical north pacific: Temporal variability. Science 1980, 209, 1522-1524. [CrossRef] [PubMed]

9. Zhang, D.; Iwasaka, Y.; Shi, G.; Zang, J.; Hu, M.; Li, C. Separated status of the natural dust plume and polluted air masses in an Asian dust storm event at coastal areas of China. J. Geophys. Res. Atmos. 2005, 110, 95-100. [CrossRef]

10. Guo, J.; Lou, M.; Miao, Y.; Wang, Y.; Zeng, Z.; Liu, H.; He, J.; Xu, H.; Wang, F.; Min, M. Trans-Pacific transport of dust aerosols from East Asia: Insights gained from multiple observations and modeling. Environ. Pollut. 2017, 230, 1030-1039. [CrossRef] [PubMed]

11. Li, W.; Shao, L.; Zhang, D.; Ro, C.U.; Hu, M.; Bi, X.; Geng, H.; Matsuki, A.; Niu, H.; Chen, J. A review of single aerosol particle studies in the atmosphere of East Asia: Morphology, mixing state, source, and heterogeneous reactions. J. Clean. Prod. 2016, 112, 1330-1349. [CrossRef]

12. Lei, Y.; Zhang, Q.; He, K.B.; Streets, D.G. Primary anthropogenic aerosol emission trends for China, 1990-2005. Atmos. Chem. Phys. 2011, 11, 931-957. [CrossRef]

13. Wu, L.Y.; Tong, S.R.; Ge, M.F. Synergistic Effect between $\mathrm{SO}_{2}$ and $\mathrm{HCOOH}$ on the Surface of CaO. Acta Chim. Sin. 2015, 73, 131-136. [CrossRef]

14. Li, W. Chemical modification of dust particles during different dust storm episodes. Aerosol Air Qual. Res. 2012, 12, 1095-1104. [CrossRef]

15. Seisel, S.; Rensen, C.B.; Vogt, R.; Zellner, R. Kinetics and mechanism of the uptake of $\mathrm{N}_{2} \mathrm{O}_{5}$ on mineral dust at 298 K. Atmos. Chem. Phys. 2005, 5, 3423-3432. [CrossRef]

16. Laskin, A.; Iedema, M.J.; Ichkovich, A.; Graber, E.R.; Taraniuk, I.; Rudich, Y. Direct observation of completely processed calcium carbonate dust particles. Faraday Discuss. 2005, 130, 453-468. [CrossRef] [PubMed]

17. Laskin, A.; Wietsma, T.W.; Krueger, B.J.; Grassian, V.H. Heterogeneous chemistry of individual mineral dust particles with nitric acid: A combined CCSEM/EDX, ESEM, and ICP-MS study. J. Geophys. Res. Atmos. 2005, 110, 1223-1242. [CrossRef]

18. Ma, X.C.; Bi, K.; Tian, H.J.; Jin, H.; Zhang, L.; Huang, M.Y. Aircraft measurements of aerosol characteristics during dust evens in Beijing. Meteorol. Sci. Technol. 2016, 44, 95-103.

19. Pósfai, M.; Axisa, D.; Tompa, É.; Freney, E.; Bruintjes, R.; Buseck, P.R. Interactions of mineral dust with pollution and clouds: An individual-particle TEM study of atmospheric aerosol from Saudi Arabia. Atmos. Res. 2013, 122, 347-361. [CrossRef]

20. Patey, M.D.; Achterberg, E.P.; Rijkenberg, M.J.; Pearce, R. Aerosol time-series measurements over the tropical Northeast Atlantic Ocean: Dust sources, elemental composition and mineralogy. Mar. Chem. 2015, 174, 103-119. [CrossRef]

21. Yigiterhan, O.; Alfoldy, B.Z.; Giamberini, M.; Turner, J.C.; Al-Ansari, E.S.; Abdel-Moati, M.A.; Al-Maslamani, I.A.; Kotb, M.; Elobaid, E.A.; Hassan, H.M. Geochemical composition of aeolian dust and surface deposits from the Qatar Peninsula. Chem. Geol. 2017, 476, 24-45. [CrossRef]

22. Yeh, C.F.; Lee, C.L.; Brimblecombe, P.; Lai, I.C. Markers of East Asian dust storms in March 2010. Atmos. Environ. 2015, 118, 219-226. [CrossRef]

23. Wang, W.; Shao, L.; Xing, J.; Li, J.; Chang, L.; Li, W. Physicochemical characteristics of individual aerosol particles during the 2015 China Victory Day Parade in Beijing. Atmosphere 2018, 9, 40. [CrossRef] 
24. Li, W.J.; Shao, L.Y.; Buseck, P.R. Haze types in Beijing and the influence of agricultural biomass burning. Atmos. Chem. Phys. 2010, 10, 8119-8130. [CrossRef]

25. Wang, G.; Zhang, R.; Gomez, M.E.; Yang, L.; Levy, Z.M.; Hu, M.; Lin, Y.; Peng, J.; Guo, S.; Meng, J. Persistent sulfate formation from London Fog to Chinese haze. Proc. Natl. Acad. Sci. USA 2016, 113, 13630-13635. [CrossRef] [PubMed]

26. Okada, K.; Qin, Y.; Kai, K. Elemental composition and mixing properties of atmospheric mineral particles collected in Hohhot, China. Atmos. Res. 2005, 73, 45-67. [CrossRef]

27. Xiao, X.H.; Shao, L.Y.; Sun, J.Q.; Zhang, N.; Li, W.J. Mineral compositions of individual particles in the inhalable particulate matter in the Lanzhou Air during heating period. Bull. Miner. Petrol. Geochem. 2007, 26, 64-69.

28. Rolph, G.; Stein, A.; Stunder, B. Real-time environmental applications and display system: Ready. Environ. Model. Softw. 2017, 95, 210-228. [CrossRef]

29. Draxler, R.R.; Hess, G.D. An overview of the hysplit-4 modeling system for trajectories. Aust. Meteorol. Mag. 1998, 47, 295-308.

30. Fairlie, T.D.; Jacob, D.J.; Dibb, J.E.; Alexander, B. Impact of mineral dust on nitrate, sulfate, and ozone in transpacific Asian pollution plumes. Atmos. Chem. Phys. 2010, 10, 3999-4012. [CrossRef]

31. Cheng, Y.; Zheng, G.; Wei, C.; Mu, Q.; Zheng, B.; Wang, Z.; Gao, M.; Zhang, Q.; He, K.; Carmichael, G. Reactive nitrogen chemistry in aerosol water as a source of sulfate during haze events in China. Sci. Adv. 2016, 2, e1601530. [CrossRef] [PubMed]

32. Liu, L.; Kong, S.; Zhang, Y.; Wang, Y.; Xu, L.; Yan, Q.; Lingaswamy, A.P.; Shi, Z.; Lv, S.; Niu, H. Morphology, composition, and mixing state of primary particles from combustion sources-Crop residue, wood, and solid waste. Sci. Rep. 2017, 7, 5047. [CrossRef] [PubMed]

33. Adachi, K.; Buseck, P.R. Internally mixed soot, sulfates, and organic matter in aerosol particles from Mexico City. Atmos. Chem. Phys. 2008, 8, 6469-6481. [CrossRef]

34. Niu, H.; Cheng, W.; Wei, P.; Hu, W. The physiochemical properties of submicron particles from emissions of industrial furnace. World J. Eng. 2016, 13, 218-224. [CrossRef]

35. Sun, Y.; Zhuang, G.; Tang, A.A.; Wang, Y.; An, Z. Chemical characteristics of $P_{2.5}$ and $P_{10}$ in haze-fog episodes in Beijing. Environ. Sci. Technol. 2006, 40, 3148-3155. [CrossRef] [PubMed]

36. Men, C.; Liu, R.; Xu, F.; Wang, Q.; Guo, L.; Shen, Z. Pollution characteristics, risk assessment, and source apportionment of heavy metals in road dust in Beijing, China. Sci. Total Environ. 2018, 612, $138-147$. [CrossRef] [PubMed]

37. Shen, Z.; Sun, J.; Cao, J.; Zhang, L.; Zhang, Q.; Lei, Y.; Gao, J.; Huang, R.J.; Liu, S.; Huang, Y. Chemical profiles of urban fugitive dust $\mathrm{PM}_{2.5}$ samples in Northern Chinese cities. Sci. Total Environ. 2016, 569, 619-626. [CrossRef] [PubMed]

38. Wu, F.; Zhang, D.; Cao, J.; Guo, X.; Xia, Y.; Zhang, T.; Lu, H.; Cheng, Y. Limited production of sulfate and nitrate on front-associated dust storm particles moving from desert to distant populated areas in northwestern China. Atmos. Chem. Phys. 2017, 17, 1-22. [CrossRef]

(c) 2018 by the authors. Licensee MDPI, Basel, Switzerland. This article is an open access article distributed under the terms and conditions of the Creative Commons Attribution (CC BY) license (http:/ / creativecommons.org/licenses/by/4.0/). 